\title{
Looking for "us": power reimagined in mathematics learning for Black communities in the pandemic
}

\author{
Lou E. Matthews ${ }^{1}$ (D) Naomi A. Jessup ${ }^{2}$ (D) $\cdot$ Ruthmae Sears $^{3}$ (D)
}

Accepted: 25 August 2021 / Published online: 16 September 2021

This is a U.S. government work and not under copyright protection in the U.S.; foreign copyright protection may apply 2021

\begin{abstract}
In this reflective essay, a BlackCrit lens is used to explore new and evolving possibilities for Black teachers, families, leaders, and students in ways that highlight and honor parents' agency, expand notions of digital equity in mathematics, and preview new and re-prioritized approaches which aid liberatory mathematics, teaching, and learning spaces that resurfaced in the pandemic. Several actions reimagine the work of mathematics as building blocks for engaging the flourishing for Black communities: (1) expanding and amplifying direct networks for Black parents to share, communicate, and advocate for their own needs and spaces around mathematics; (2) making visible and amplifying our advocacy for racial justice in the content creation and representation found in current digital platforms for meeting the needs of Black communities; and the need to (3) invest in, prioritize usage of, and illuminate mathematics commercial and academic entities focused solely on creating content and centering Black (and other people's) knowledge and experiences in mathematics for Black families.
\end{abstract}

Keywords COVID-19 · Black communities · Digital equity $\cdot$ Culturally relevant mathematics teaching $\cdot$ Parents and mathematics learning

As the coronavirus 2019 (COVID-19) pandemic disrupted the world, a compounding social pandemic forced an awakening for others to the horrors of police brutality and systemic racism simultaneously affecting Black communities in the United States (US). In a matter of weeks of the onset of the pandemic, the communities where we, the authors, live

Naomi A. Jessup

njessup@gsu.edu

Lou E. Matthews

Lou.matthews@urbanteachers.org

Ruthmae Sears

ruthmaesears@usf.edu

1 Urban Teachers, Baltimore, MD, USA

2 Early Childhood and Elementary Education, Georgia State University, Atlanta, GA, USA

3 Department of Teaching and Learning, University of South Florida, Tampa, FL, USA 
and work experienced pronounced health disparities and waves of disruption from physical lockdowns to economic shutdowns. As African American and Black Caribbean scholars, we have felt this sharply in the communities we live, and those we serve. We have been directly and indirectly affected by the disproportionate number of Black ${ }^{1}$ people hospitalized because of COVID-19 (see Garg, 2020), and the unequal representation among "who gets infected, who gets tested, and who dies" (van Dorn et al., 2020). In addition, our resolve has been tested, with others, through physical lockdowns, economic downturns impacting our small businesses and centers, and emotional challenges of diminished church and social gatherings. The first author reflected on the stress of the pandemic in this way:

I belong to a FB [Facebook] group with about 10,000 predominantly Black community members. I remember one member talking about members of her family who were sick and contracted COVID-19, and two that died from it. She asked us [the FB group] to pray and from that moment, the pandemic really hit home. At that moment, we [the FB group] dropped everything to respond with comments of encouragement and hope...I'm afraid to look at my timelines across social media. I'm feeling this onslaught in our community.

\section{Historical backdrop}

As Black mathematics scholars, teachers, and activists during the COVID-19 pandemic, it compelled us to make important shifts in our practices of supporting mathematics teaching and learning. Our research and activism are heavily influenced by supporting Black learners in places we live, knowing the US historical legacy of educational malpractice and anti-Blackness dating before the $1600 \mathrm{~s}$. The US has a long-documented history of disenfranchising educational spaces for Black learners (see Hillard, 1991; Horsford, 2011, among others) which Gloria Ladson-Billings (2006) refers to as the "education debt." Ladson-Billings (2006) describes education debt as an accumulation of historical, economic, sociopolitical, and moral inequities for Black, Latinx, Indigenous, and Asian children. For example, the US Supreme Court decided in the Brown vs Board of Education (1954) case that segregated Black public schools did not have comparable and adequate access to support learning (e.g., buildings and curriculum) and violated the Equal Protection Clause. During that time, the nation viewed the decision as a turning point in American history toward a national consensus for educational equity (McNeal, 2009). However, McNeal (2009) notes that even 50 years after the Brown decision, the US Department of Justice 2008 reported 276 school districts had yet to fulfill court mandates for racial desegregation of public schools and educational inequities continuously abound.

The continual residue of not doing right by Black communities continues to persist within mathematics educational spaces (Davis \& Jett, 2019; Gutiérrez, 2013; Martin, 2019) and do not acknowledge the generational violence caused to Black communities (Martin et al., 2019). We note the impact of COVID-19 as the roles and responsibilities of replicating school-based learning moved in the homes of many Black families. These responsibilities fall on the shoulders of parents and caregivers, whose cultural wealth and practices were often excluded, ignored, or not valued (Allen \& White-Smith, 2018; Martin,

\footnotetext{
1 Moving forward we use the term Black to represent the African Diaspora reflected in our ethnic and cultural identities.
} 
2006). Our work situates the impact of a "legacy of educational injustices" (Ladson-Billings, 2006) of mathematics instruction for Black communities in the US during COVID19. Thus, we have a collective heightened sensitivity to ensuring that Black families are well cared for during and after the COVID-19 pandemic. As a result, our reflections have opened up a space to reimagine our work within mathematics for Black learners in our communities. In this essay, we provide a reflective account of our group's experiences at this moment, in concert with certain theoretical considerations from the broader literature. Using a BlackCrit perspective, we aim to discuss (1) the nature of power dynamics and roles connected to mathematics learning in Black homes, (2) our renewed interest in digital equity, and (3) our expanding notions of mathematics content that harness excellence and flourishing for Black learners.

\section{Our collective contexts}

As the coronavirus 2019 (COVID-19) pandemic disrupted the world, concurrent events of anti-Black racism forced a global awakening to the horrors of police brutality and systemic racism (Wagner et al., 2020). Thus, the stress experienced by the pandemic for many Black people in the US was compounded by racial tensions (Lund, 2020). As African American and Black Caribbean scholars in the US, in this reflective essay, we engage in strategic essentialism (Pande, 2016) in using pronouns such as us and we to speak about the collective experience faced by Black communities in the US while acknowledging the impact was not the same for everyone.

Because of the abrupt changes to all facets of daily life, the Black communities where we live and work experienced pronounced health disparities and waves of disruption from physical lockdowns to economic shutdowns (Lund, 2020; Nicola et al., 2020; Yang $\&$ Carter, 2020). There is a disproportionate representation of COVID-19-related deaths and hospitalizations for Black people. The Center for Disease Control (2020) reported that $74 \%$ of US children and teens who died from COVID-19 were Latinx and Black, despite comprising only $40 \%$ of the US population (US Census Bureau, 2020). The shelter-inplace guidelines and physical lockdowns created economic and emotional challenges, while small businesses, churches, and community centers/clubs-all critical anchors in Black communities - closed, some indefinitely. These closings affected how Black residents worked, worshipped, and lived, creating a domino effect of disruptions that strained resources in homes as some families coped with shortages of food and other necessities. As a result, many Black families faced an additional economic pandemic (Kantamneni, 2020), increased mental health disparities (Lund, 2020; Yang \& Carter, 2020), which reflects the global accounts of the impact of COVID-19 on marginalized communities (Nicola et al., 2020; Prime et al., 2020). Readers may note parallels to the pervasiveness and impact of disparities that exist globally across social markers such as race, gender, class, and ethnicity (Beaman \& Petts, 2020; Chmielewski, 2019; Stash \& Hannum, 2001; Unterhalter, 2005). 


\section{Our positionality}

As African American and Black Caribbean scholars in the US, we acknowledge and embrace our complex positionality as scholars and residents currently in key urban centers in the US. We connected online through mutual participation in an online network of mathematics education focused on equity, and the experience of collaborating throughout the pandemic has bonded us. As authors, we actively engage in scholarship that examines curriculum issues, facilitates professional development, and supports parents in the teaching and learning of mathematics for Black learners. Collectively, two authors reside or work in cities where roughly $50 \%$ of the population is Black (i.e., Washington, DC and Atlanta, GA), and 25\% for the third author (Tampa, FL). The first and third authors have strong Caribbean ties, being born and raised in Bermuda and the Bahamas, and maintain strong professional communication with colleagues and family there.

Together, we share over 70 years of combined experience in P-20 mathematics focused on various areas such as culturally relevant mathematics pedagogy and digital equity. We offer our perspectives and experiences and simultaneously acknowledge our tension in speaking to the collective weight of these experiences, while not essentializing or limiting the complexities of Blackness. As Black scholars, we have continued to probe Martin's question (as cited in Aguirre et al., 2013), "What does it mean to be Black in the context of learning and doing mathematics?" We consider our role as practitioners. The enterprise of mathematics (that is, how we come to organize, promote, and lead school mathematics) is an important place of disruption because of our positionality. We extend this "public narrative" to prod, "What does it mean now, for us and our people?" during the COVID-19 pandemic.

\subsection{The disruption of mathematics learning from a BlackCrit/anti-Blackness perspective}

As Black mathematics education scholars who take part in community activism, we draw on BlackCrit theory that specifically acknowledges anti-Blackness as endemic (Coles, 2020; Dumas \& Ross, 2016) and confront the anti-Blackness within the disruptions of mathematics learning for Black learners. BlackCrit, a subgroup of critical race theory, is conceptualized by Dumas and Ross (2016) around three ideas: (1) anti-Blackness is endemic and central to how we make sense of multiple dimensions of resistance (e.g., socially, historically, economically), (2) tension exists between multicultural and diversity efforts that are often in opposition of Black people flourishing, and (3) the creation of liberatory spaces that disrupt dehumanizing conditions and provide avenues of hope. BlackCrit helps us to analyze how the specificity of anti-Blackness matters in explaining how Black bodies become marginalized, disregarded, and disdained in schools and education spaces (Dumas \& Ross, 2016; Gholson \& Wilkes, 2017; Martin, 2019; Warren \& Coles, 2020). In the sections that follow, we frame our discussion around these pertinent areas:

(1) Highlighting how Black parents express agency in their roles in mathematics learning during the pandemic; 
(2) Challenging the status quo of digital equity approaches to mathematics and a critique of policies that marginalize Black students' and promote digital inequities; and.

(3) Previewing new and re-prioritized approaches to mathematics, teaching, and learning that represent a re-imagination of liberatory mathematics spaces that support Black learners thriving.

\section{Power dynamics for Black parents and families}

In this section, we acknowledge points of disruption in the vision of mathematics learning and the potential for Black families and communities that radically shift participation in structures of mathematics learning in promising ways. Mathematics education spaces historically position parents as obstacles in meeting a reform-based vision of mathematics learning and view their roles as passive recipients of information (Peressini, 1998). We want parents to do what we say with the information and resources given, without question. Yet, they view Black parents as uninvolved (McGee \& Spencer, 2015; Schnee \& Bose, 2010; Yosso, 2005) and untrustworthy with school resources (Jackson \& Remillard, 2006). In addition, Black parents are viewed from a deficit lens, assumed to lack knowledge, and only as recipients of information (Pereressini, 1998). There is limited attention to Black parents' racialized experiences (Martin, 2006), oppositions to school-centric views and ideologies of involvement, and how employment affects the allocation of time for supporting learning. A BlackCrit lens allows us to view Black parental involvement and resistance as more nuanced, and we have seen firsthand this kind of resistance in several instances. Typically, the scenario is that of a parent asking for affirmation, or flatly informing us they had to make alternative decisions about mathematics tasks, demand, or methods. What should we make of this? Isolated or not, the agency of Black parents in mathematics is critical for the liberatory mathematics we wish to imagine. We know when schools "meaningfully" partner with families across race, class, cultural backgrounds, and education, families can positively influence their child's learning and identity development (Bridges et al., 2012; Brown, 2019; Ing, 2014). We believe that the COVID-19 pandemic has pushed schools to reconsider the extent of their partnerships and relationships as learning occurred virtually and schools sought parents to support their child's mathematical learning. This line of thinking seems promising but further interrogation is needed of the ongoing legacy of disregarding (and voiding even) Black parents' social capital (see for example, Yosso (2005)) in educational spaces. A BlackCrit lens provides space for us to illuminate the liberatory and rehumanizing approaches to learning mathematics created by Black parents as roles and responsibilities were abruptly shifted during COVID-19. We discuss this shift in power dynamics for parents and families in two ways: (1) the tension in the recognition of Black parents' social capital and partnership in supporting mathematics learning and (2) the agentive practices of Black families as they push back on school-based ideals of mathematics learning.

\subsection{Oh, now they see us and need us}

From our multiple vantage points in working directly alongside Black communities, we noticed how the move to remote learning because of the COVID-19 pandemic thrust 
schools and school systems into recognizing their own fragility in supporting learning. In these instances, schools finally recognized parents and caregivers in their roles in supporting their children's learning. It forced the school systems to rely on established or nonexistent partnerships among individual schools and families in supporting mathematics instruction. The reliance of schools working alongside parents is an illusion, particularly for many Black families because the relationships between the school and home are often strained. These strained relationships are often because of the multiple manifestations of mistrust placed on Black families and perceptions that Black parents are less engaged with their child's academics (McGee \& Spencer, 2015). Therefore, concerns often arise in Black communities because of a lack of mutual trust and respect of parents among teachers and schools.

Yet with the urgency of "presumed learning loss," Black parents were suddenly inundated with communication from schools and teachers more than ever before. In a discussion between the second author and a Black parent around understanding the directions on a fourth grader mathematics worksheet, the parent shared her frustrations that suddenly, her child's teacher was sending home several emails regarding work that needed to be completed, how work should be uploaded, and links to potential resources if the child was having difficulties. She shared,

I think what is even more frustrating is that it's not like I haven't tried to reach out to this teacher before [COVID-19]. I have and I got nothing. But now, we [both parents] get weekly and almost daily emails and reminders about what needs to be done, how to show their work, and what I can do if our child doesn't understand the work. It's like, oh, now you see us and need us. (personal communication, B. Thomas, September 10, 2020)

We believe this scenario resonates with many Black parents in our circles. Many had limited interactions with their child's teacher before COVID-19, but were now unexpectedly responsible for supporting and providing resources to support their child's learning based on the school's guidelines and expectations. Not surprisingly, some Black parents in our communities shared anxiety in completing school-assigned packets, online learning modules, and the struggle to guide the learning of mathematical concepts. This form of anxiety and frustration mirrors the espoused tensions of Black parents seeking to help their children in learning mathematics through newly adopted curriculum (see Jackson \& Remillard, 2006). It was precisely this concern that led the first author to create an online internet community of 400 members and a weekly live video broadcast focused on ".....Holding critical conversations around mathematics and resources that help children, teachers and families shine and create spaces that amplify and illuminate the voices and images of Black children, families, and community in the mathematics space" (Pi Before Dinner-Math Inspiration Community, 2020). We note the shifts in roles for engaging in school-based mathematics into Black homes take place when these same Black communities are experiencing an increased risk of exposure as essential workers, high mortality rates, and health disparities. We are mindful of the extraordinary pressures being placed on Black people in our circles and focus attention on improving care systems. Brown (2019) reminds us that people are often blamed for what did not happen instead of considering systemic issues that impeded their progress. 


\subsection{Agency in mathematics learning for Black families}

The displacement of mathematics learning meant a reliance on parents to disseminate school-based visions of mathematics teaching and learning and opportunities for Black families to challenge and change those visions. Therefore, another aspect related to power dynamics we encountered was through the agentive ways Black parents and caregivers were drivers of at-home, hybrid, and online mathematics learning in more expansive ways. The extent of including their children's identities and experiences within mathematics instruction was exposed, leading to more opportunities for questioning the vision of mathematics learning presented by schools. Black parents could visibly see the anti-Blackness in school-created visions of mathematics learning that often ignore the identities, realities, and lived experiences of their Black learners (Martin, 2012, 2019: Martin et al., 2019).

On the surface, schools and Black parents working together with a unified vision appear promising. However, the current vision of school mathematics often perpetuates a one-size-fits-all universal approach to mathematics for Black children, which is problematic. The invisibility of Black children in the curriculum and a standardized approach maintains school mathematics as a White institutional space that has been a historical feature of the experiences of Black children (Bullock, 2019). Essentially, schools are asking Black parents to reproduce and recreate problematic ideologies that further increase inequities for their children (Berry et al., 2014; Bullock, 2018; Larnell, 2016; Martin, 2013; Martin et al., 2019), and worse, mirror negative experiences faced by Black parents as students in the past (Martin, 2006; McGee \& Spencer, 2015; Remillard \& Jackson, 2006).

However, considering the COVID-19 pandemic and shift in power and responsibility of Black parents and caregivers, the legitimacy of the institutionalized authority of schools was questioned. The pandemic has provided some Black parents more opportunities to make more direct decisions around appropriate mathematics content. In conversations with Black families in our networks, frustrations arose regarding the poor quality of materials given to families for instruction. These frustrations echo sentiments that scholars have reported that before the COVID-19 pandemic. Teachers of Black children devoted less time and emphasis on developing critical thinking skills, engaged in less challenging curriculum, resulting in a continuous cycle of curricular violence that furthers their opportunity gaps (Ladson-Billings \& Tate, 1995a; Martin, 2012, 2019). Unfortunately, these opportunity gaps were not erased during COVID-19 but allowed Black parents firsthand knowledge of their children's mathematics learning experiences.

One form of "mathematics instruction" schools provided during remote learning included a series of packets of mathematics worksheets. Teachers expected students to complete these packets with no interaction or scaffolding from them. Black parents in our community networks communicated that the work did not emulate high-cognitive demand and intellectual and cultural rigor. As a result, we witnessed some parents making critical content shifts and decisions they determined were in the best interest for their children. For example, one Black parent shared how the school's initial introduction to add within 10 (e.g., K.OA.3 Common Core State Standard for mathematics) was through solving a series of equations. The parent wrestled with continuing to follow the schools' plan and questioned the appropriateness of introducing addition without context to Kindergarteners. She took action by incorporating manipulatives to allow her child to model mathematics and increase cognitive demand. She stated, 
It was my daughter's first formal exposure to addition, although we have been doing it experientially since birth. So, as a parent, I guess I question when you know that something is too simple [adding within 10], when is it okay to move forward... [pause], even when it is the first time introducing something [adding within 10] and trusting the child to show you what level they are on? I wanted to make sure we [her and her daughter] do not miss fundamentals [provided by the worksheet], but my daughter was like, "this is too simple." I added dice, some bears, and she liked the new activity [adding manipulatives]. My daughter also likes telling stories [the equations were changed into story problems], and just having [adding] two numbers were "dry"...I thought it would be confusing adding more than two numbers - but I was wrong (personal communication, T. Tyrell, April 8, 2020)

When parents show this kind of agency, by extending intended goals, shifting methods, and repositioning children as co-creators of the math, they practice centering the identities and experiences of their Black child.

\section{Centering the focus on high quality digital mathematics content}

COVID-19 pandemic's impact on school has meant the dramatic increase of and attention to digital platforms and remote virtual instruction for families in Black communities we serve. In the US, schools and districts turned to digital platforms and remote learning in order to maintain mathematics learning in the pandemic. This rapid change in modality for learning caused alarm and concern for digital access for mathematics learning in our communities. Many in our circles had to accelerate their adaptation to (and comfort levels with) popular graphing software, while others were challenged to consider new online platforms and content previously accessible in classrooms. Access to and engagement with rigorous mathematics should happen regardless of whether they offer the curriculum face-to-face or via a digital platform (Reich, 2019). Even now, digital equity remains as important now as it has in the past. We also realize that technology alone cannot eradicate the history of educational malpractice and negligence for Black learners of mathematics.

Digital equity has been framed as issues with access to: (1) internet connection, (2) quality content, (3) content creation, (4) skilled educators, and (5) enhanced learning based on applications of digital technologies (Resta \& Laferrière, 2008). Like every other educational space, there is a need to scrutinize this conceptualization of digital access for Black communities. In our own experiences, digital equity, as described above, has not been centered in major mathematics equity work featuring Black children. We ask if our experiences within our communities are taken up by this notion. If not, what should be central, and what more can we imagine. In this manner, aspects of digital equity such as quality content and content creation stand out. In the sections below, we share tensions from our reflections juxtaposed with current theoretical positions on digital equity.

\subsection{Of course, access to digital learning [still] matters}

The obvious issue with digital learning platforms seen through the lens of digital equity is access to digital platforms, tools, and the internet, in general. The pandemic has given us a renewed sense that much of what we, and others, focus on as excellence in Black 
mathematics education has not fully encompassed the critical fit of digital equity concerns of access. We envision communities where Black children can have unfettered access to the internet as they engage in mathematics experiences that support them in flourishing. In the space of the COVID-19 pandemic, we have seen this exasperated. Prior to COVID19, Black households in the US with school-aged children were reported as having the second largest percentage of households that lacked high-speed home internet affecting 3.25 million Black children (US Joint Economic Committee report, 2017), and we have experienced this within our networks. For example, in the Bahamas, home of one author, less than $30 \%$ of students are enrolled in the government-operated digital platform (Smith, 2020). While in Bermuda, another home of another author, our teacher friends and colleagues have shared unreadiness and uneasiness with what digital offerings have already rolled out, and the work structures set up to teach children (Bermuda Ministry of Education, 2020).

Although both countries have created mechanisms to provide digital access, there has been real unease with how families will access digital learning experiences in critical times. We share this concern in each of our spaces. Mathematics is a critical academic gateway and disrupted participation in quality mathematics experiences carry stark circumstances. This disruption has meant that too many Black children had interrupted access to quality digital mathematics experiences. For one, we agree that the lack of access to the internet during the pandemic can have significant tracking implications on the mathematical paths Black students are encouraged to take in future academic years (Berry et al., 2014; Kelly, 2009). This lack of access comes even as tracking has become a major focal point for equity concerns in mathematics.

\subsection{Looking for "us" online: seeking and finding quality content}

Early in the pandemic our attention to digital equity comprised concerns about access (issue 1). This agenda soon broadened into concerns for the quality of digital content (issue 2), and lack of Black representation in creating digital mathematics content (embodied in issue 3 ). In one encounter, typical to this concern, parents would routinely ask us for online recommendations for digital platforms and tasks that could supplement what they believed lacked both challenge and relevance. For example, one parent sought help to move beyond a pandemic cycle of picking up, working through, and returning weekly 'packets' of mathematics work. Parents and teachers wanted supplementary and alternative online programming to support what they perceived as non challenging school work. Because of this, one of the Pi Before Dinner videocasts, created to engage our online communities in mathematics, focused on online math intervention programs. In interviewing the directors of two leading elementary math programs, we wondered why the interests of Black children and families were not centered in content and context creation in their product offerings.

Matthews (2018) has posed, "why are so many publishing, promotional, exhibit, and professional development interests missing people of color in ownership, contracts, and presence?" The pandemic has caused us to extend this search for "us" in the digital images and representations that might serve as inspiration and intervention for Black families in mathematics. Too often in our search, we experienced images of Black children in scenes depicting struggle or images buried deep within "clicks" away from the home page. The reimagining of Black images and even Black mathematical "doing" is critical to our liberatory aims. Ultimately, implementing high-quality mathematics via digital platforms for Black communities in this time of the pandemic should (1) capitalize on parental 
contribution to their children's learning (McGee \& Spencer, 2015) and (2) provide opportunities to authentically engage students' family and make room for outside interests (Reich, 2019), a point we further explore in the last section. We want to see Black learners thriving on digital learning platforms.

\section{Mathematics, now}

In the previous sections, we have examined parent agency, and our reflections on digital equity. Each of these has led us to question the very nature of mathematics' relevance for fulfilling the liberatory interests of Black communities. The COVID-19 pandemic has led to a disruption in the status quo of what mathematics communities use and prioritize. In reimagining mathematics learning, we consider Martin's et al. (2019) declaration: "we define black liberatory mathematics education as the framing and practice of math education that allows Black learners to flourish in their humanity and brilliance, unfettered by whiteness, White supremacy and anti-blackness" (para. 4). What does this mean for the moment we find ourselves in? We think the time is right to further challenge our collective work in promoting culturally relevant mathematics experiences. We also expand our investment in what mathematics can be in mathematics as love, which is explored later in subsequent sections.

\subsection{Raising culturally relevant mathematics to the power of the people}

Culturally relevant teaching (CRT) is prominent in our collective and individual research, group affiliations, and pedagogy. For us, CRT makes it possible to reimagine mathematics for thriving in Black communities. The introduction of culturally relevant/responsive pedagogies in the mid-late 1990s re-imagined schooling and mathematics experiences for Black communities (see Enyedy \& Mukhopadhyay, 2006; Gutstein et al., 1997; Leonard \& Guha, 2002; Matthews, 2003; Tate, 2004). Culturally relevant teaching (Ladson-Billings, 1994) used interchangeably ${ }^{2}$ in practice with culturally responsive (Gay, 2010) and, more recently, culturally sustaining (Paris, 2012), has described how teachers prioritize (1) academic excellence, (2) the affirmation of culture and identity, and (3) the commitment critical consciousness and collective action. CRT describes exemplary teacher practices that work to empower students academically while building strong cultural, social, and political identities (Gutstein et al., 1997; Ladson-Billings, 1994, 1995a, 1995b; Matthews, 2003; Sleeter, 1997; Tate, 1995).

CRT has been essential for reimagining during this moment. The COVID-19 pandemic, on top of the continual systemic problems of police brutality, and racism in Black communities have sparked (and in cases rekindled) urgent conversation about Black identity and care beyond the required curriculum. As Ortiz and Ruwe (in press) argue, CRT allows for the sustainability and affirmation of Black identities through a mathematics curriculum that supports critiquing and navigating the world. For our work, we make use of CRT, which

\footnotetext{
${ }^{2}$ For the purpose of this work, we make no attempt to distinguish, practically, between culturally relevant, culturally responsive, and culturally sustaining. In practice, the terms share important commonality that is at the center of this work. It should be noted that in research circles, they represent markedly distinctive vantage points, each having rich and growing veins of literature in and outside of mathematics.
} 
embodies Black thriving by helping educators transform mathematics pedagogy, content, and, more recently, the tasks associated with content that center Black learners and their experiences.

Culturally relevant mathematics tasks are (1) centered in cultural and community inquiry and (2) purposed for individual and collective critical agency and (3) mathematically rich (Gutstein \& Peterson, 2013; Jones, 2015; Matthews et al., 2013; Ortiz \& Davis, 2020; Turner \& Strawhun, 2007). Even more nuclear to this discussion is the heightened urgency for these tasks in our spheres of influence. For example, in one of the first authors' Pi Before Dinner weekly shows, the adaptation of mathematics tasks has shown up in conversation with parents (and teachers) of Black children who have openly broken rank with the monotonous brand of mathematics tasks and "worksheets" being provided by schools. The break in status quo is emblematic of the expanded opportunities to explore the sociocultural and sociopolitical environment in their homes. Below is an example of a type of modification discussed on the weekly shows by the first author related to the rehumanizing procedural work of dividing fractions by fractions and including a culturally relevant context. This specific example was also previously presented during collaborations with colleagues in Baltimore around rehumanizing fractions:

The transformation of the division problem in Fig. 1 took on even greater significance for the group of Baltimore teachers who served predominately Black children. These Baltimore teachers worked in a city hard hit by economic challenges and the adaptation of the fraction division problem aimed to center mathematical and sociocultural inquiry on these challenges. In the Pi Before Dinner discussion, this type of adaptation to mathematics tasks occurred with Black parents during COVID-19, and tools for those parents to push back against the (anti)blackness their children were encountering during remote learning.

The task above provides a muse for discussion and probing at the nature of critical inquiry in elementary mathematics problems itself. The adaptation we discussed in the fraction problem above also made its way into at least one author's coursework planning for a teacher residency program called Urban Teachers. In this application, core assignments were deliberately changed to challenge teachers with creating or adapting culturally relevant mathematics tasks with greater attention to anti-racism and social justice. Prioritizing the "now" of Black life in our communities within culturally relevant mathematics task making has been made possible for two reasons. First, the language of the pandemic has been encased in common mathematical language through a variety of mathematical models, tables, and concepts that require interpretation, acceptance (or disruption), and engagement. One of the more embedded vocabulary has been "flattening the curve," a

Fig. 1 Example of a rehumanized fraction division problem
Rehumanizing Fractions

$$
\begin{gathered}
\text { Review } \\
\frac{5}{6} \div 1 / 3
\end{gathered}
$$

The city of Baltimore has designated five-sixths of an acre to support local pop-up stores as part of an urban initiative. One proposal calls for the division into one-third acre lots.

Does the proposal offer ample opportunity to entreprenuers? 
reference to the modeled exponential growth curve of the virus spread and its potential to overwhelm public health service systems. Crafting a culturally relevant mathematics task in this way might include examining how COVID-19 recovery rates vary amongst cities and states, allowing them to analyze community responsiveness through a variety of sociopolitical lens. Similarly, students might use business application problems like the one illustrated above to explore economic resilience and recovery.

The pandemic shift potentially repositioned many of the Black homes in our communities as asset-rich environments through which children and their families might use mathematics as tools in anti-racism efforts. So, for this second reason, positioning the Black home in mathematics making is critical in building collective agency for racial justice. We have seen the need for culturally relevant mathematics tasks to play an active role, given the current racial climate across the US, to equally, critique and disrupt how data has been withheld, misstated, distorted, and weaponized in its use towards Black people. For example, the Georgia Department of Public Health disseminated distorted data about the number of deaths and hospitalization that showed a steady decline in confirmed COVID-19 cases. An examination of these distortions within the context of mathematical inquiry (in this case, measurement and data) carries the potential of illuminating patterns of injustice impacting Black families. Concerns about the disproportionate impact of COVID-19 on Black communities, magnified with the ongoing protests around police brutality, serve as a parallel context in which we write. Hence, the pandemic discourses have already curated a "curriculum" of meaningful, relevant mathematics topics.

\subsection{Pushing mathematics to love}

The compounding impact of the pandemic's impact on Black families and Black Lives Matter protests against police brutality and entrenched racism has had a profound impact on us, individually and collectively. This era has opened the door for new conversations about care, identity, and thriving as Black mathematics educators that our training and education have not prepared us. In sum, in the work of reimagining liberatory mathematics, we tasked ourselves to do work with, and for our people, while simultaneously mitigating the ongoing impact to our Black bodies, our families, and our philosophies. The work for us (e.g., task making, methods coaching) has been in a state of constant flux, to a heightened degree than before.

Faced with the social challenges exasperated during the COVID-19 pandemic for Black communities, we reimagine a practical ethos of mathematics as love. Education social commentator and scholar Chris Emdin (see Matthews, 2018) injected into the public narrative of mathematics an orientation for teaching mathematics is grounded in love. Matthews captured this orientation, mathematics as love:

Mathematics as love, is a counter space to those who overly tout the beauty in mathematics. Under this public narrative, mathematics, particularly its beauty, is often stated, referencing exquisite (another mathematics word ported into elite language) abstract shapes, processes, and algorithms are presented as objects of beauty.

Mathematics as love stands in contrast to the love for mathematics mantra, that through our critical lens, is often positioned to demonize Black learners (and other learners) in achievement gap conversations in our networks. Rather than forcing the "learner" to consider their "feelings" and motivations for mathematics, this orientation is subtle, because it requires reciprocity from educators in how engagement in mathematics prioritizes 
caring for the human condition (love), both individually and collectively. Within the lens of BlackCrit, we see this as a disruption to the status of math work, as it is a commitment to the thriving of Black people-our people.

As Black scholars working alongside Black teachers, parents, and leaders, the COVID19 pandemic has illuminated for us how mathematics as love might be operationalized more prominently in the discourse around mathematics teaching and learning in our communities. The displacement of Black people in the pandemic, compounded by the ongoing dehumanization of Black Lives against police brutality, has created opportunities to reflect on individuals' experiences in the Black community and the care they receive inside and outside the classroom setting. The ethic of care gives rise to different questions.

Mathematics as love is an "ethic of caring" perhaps best captured in Noddings (1984) book, Caring: A Feminine Approach to Ethics and Moral Education: "As human beings we want to care and to be cared for" (p.7). Current efforts in re-humanizing mathematics affirm this ethic because doing so seeks "connections, joy, belonging" (Gutiérrez, 2018, p. 4) as part of the mathematics experience. A key to an effective implementation of mathematics tasks, discourse and actions is a personalized connection to human conditions, which foster healing relationships and affirmation (Matthews, 2018). Teaching and practicing mathematics from a love orientation is to explicitly design mathematics tasks, courses, and programs that work consciously to alleviate the human condition through mathematical inquiry and engagement. It centered relations in mathematics learning so that mathematics doers might reside closer to the human condition, rather than merely operating on it. In this love orientation, we expand the contexts of teaching fractions beyond dividing pizzas and chocolate bars; measurement for finding perimeters of imaginary rectangular boxes; finding $\mathrm{x}$ for the sake of solving context-less one- and multi-step equations.

For us, mathematics as love presents immediate tensions with how we are normalized to think about the subject. As scholars, we continue to struggle with how this orientation changes our work. We find one operational application in the mathematics lesson

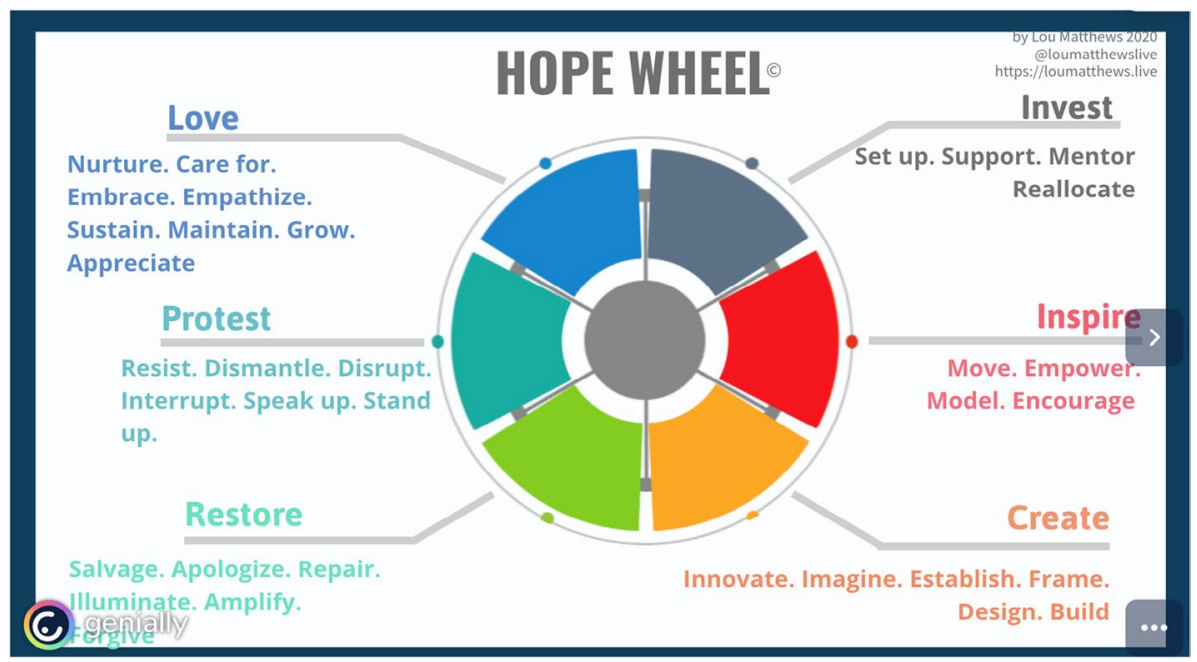

Fig. 2 Hope Wheel Mathematics Lesson Planning Tool 
planning tool called the Hope Wheel, created by the first author, helps teachers plan instruction experiences beyond verbs typically found in Bloom's taxonomy (see Fig. 2) that provide space for Black learners to flourish. The tool itself was created for the sole purpose of supporting educators to plan differently at the height of the pandemic and racial protests of 2020. We envision intentionally crafted, "hope-driven," instructional objectives such as "Students will disrupt narratives on local gentrification by examining nonlinear relationships between local investment, employment and housing variables" alongside, or in place of, standards-based objectives like understand, investigate, and represent. The apparent tension comes not with the tone of the objectives, but rather their fit with existing planning norms which rarely prioritize care in formal objectives-setting.

The Hope Wheel, as with culturally relevant mathematics teaching, is not a panacea for Black communities, but represented expanding and urgent opportunities during the crises to rise to the challenge of repurposing mathematics content for healing, inspirational experiences, and addressing ongoing traumas.

\section{Conclusion}

In this essay, we reflect on possibilities for our mathematics with Black teachers, families, leaders, and students in our communities. Using a BlackCrit lens, we have sought to highlight and honor parents' agentive practices, sharpen our notions of how digital equity might work with families in mathematics, and challenge how our pedagogical approaches aid liberatory mathematics learning for Black children. In doing so, we acknowledge certain tensions and challenge ourselves with some disruptive actions that both affirm and model practical next steps. The assertions made here are representative of the critical issues we see across the boundaries of our personal affinity with and professional responsibility for Black community.

Again, "we" is used as a term in strategic essentialism-not to provide an all-knowing gaze into the unknowable and complex make-up of Black-representative communities. Rather, we use the term in solidarity, mostly affectionately, and almost certainly in the liberatory moment. Our writing through the BlackCrit lens is a call to action for, and in, the communities we reside and work. Taken together, we believe this call means something beyond us. We contend it speaks to collective struggles and challenges for Black people (to varying degrees) in other spaces - it should be seen as a window and mirror through which we might also explore those struggles. Black community in the way we say it is both plural and singular in ways that are flexibly and dynamically called upon in moments of challenge. We see this complexity as a challenge to share our voices and inspire similar voices to stand in solidarity and create spaces for humanizing educational opportunities and equitable outcomes.

The work we have embarked on together has made us cognizant, not only of power shifts, but of the complex interplay of power, ownership, access, representation, and knowledge in and around the mathematics learning for Black learners which requires increased attention during the COVID-19 pandemic (Jessup et al., 2021). It is also clear that this interplay happens in ways that challenge, not only our existing knowledge base (of content and methods), but also our humanity. The latter of these has been absent from how mathematics enters into the lives of professional educators and how prepared they are to act on the human condition with care and love. The pandemic has been a stark reminder of that reality. 
We recognize that anti-Blackness in education occurred before COVID-19, during COVID-19, and has the propensity to remain afterwards if collective efforts of resistance and reimagining occur as voices and accounts of Black people's lived experiences are listened to, considered, and acted upon. Additionally, we have used the term liberatory to refer to how Black learners and communities thrive in the individual and collective sense. This liberatory emphasis, for us, is a work in progress, and we do not claim that in this reflective essay that we have recounted what liberatory is or looks like. Given what has been shared, we continue the conversation for the reimagining of mathematics for our communities and consider building blocks for those similarly engaging in the flourishing for Black learners:

1. Expanding and amplifying direct networks for Black parents to share, communicate, and advocate for their own needs and spaces around mathematics

2. Making visible and amplifying our advocacy for racial justice in the content creation and representation found in current digital platforms for meeting the needs of Black communities, as well as the need to

3. Invest in, prioritize usage of, and illuminate mathematics commercial and academic entities focused solely on creating content and centering Black (and other peoples) knowledge and experiences in mathematics for Black families.

We construct the actions above in ways that position us, both within and alongside Black communities, as agents in shifting power away from the current model of mathematics learning production towards one of shared power relations. The actions mentioned above are not mutually exclusive nor exhaustive. Mostly, they speak to the spheres of influence of each of the authors. Using verbs like expanding, making visible, amplifying, investing, prioritizing, and illuminating is deliberate and represents a form of activism in creating space of alternative, interdependent structures within and with-out mathematics education. This reimagining is unfinished work, both in our imagination and practice. We suspect that additional actions, different actions, in connection, collaboration, and relationship with Black communities are needed and welcome further dialogue and action that might establish a more fulsome agenda in this pandemic renaissance.

\section{References}

Aguirre, J., Mayfield-Ingram, K., \& Martin, D. (2013). The impact of identity in K-8 mathematics: Rethinking equity-based practices. The National Council of Teachers of Mathematics.

Allen, Q., \& White-Smith, K. (2018). "That's why I say stay in school”: Black mothers' parental involvement, cultural wealth, and exclusion in their son's schooling. Urban Education, 53(3), 409-435. https://doi.org/10.1177/0042085917714516

Beaman, J., \& Petts, A. (2020). Towards a global theory of colorblindness: Comparing colorblind racial ideology in France and the United States. Sociology Compass, 14(4), e12774.

Bermuda Ministry of Education. (2020, May 10). Video: Minister Rabain Q\&A on public education. Retrieved from http://bernews.com/2020/05/minister-hold-facebook-qa-public-education/

Berry, R. Q., III., Ellis, M., \& Hughes, S. (2014). Examining a history of failed reforms and recent stories of success: Mathematics education and Black learners of mathematics in the United States. Race Ethnicity and Education, 17(4), 540-568. https://doi.org/10.1080/13613324.2013.818534

Bridges, B. K., Awokoya, J. T., \& Messano, F. (2012). Done to us, not with us: African american parent perceptions of K-12 education. Frederick D. Patterson Research Institute, UNCF. 
Brown, A. C. (2019). Engaging and embracing black parents. In L. Delpit (Ed.), Teaching when the world is on fire (pp. 119-127). The New Press.

Brown v. Board of Education, 347 U.S. 483, 74 S. Ct. 686, 98 L. Ed. 873 (1954).

Bullock, E. C. (2018). Intersectional analysis in critical mathematics education research: A response to figure hiding. Review of Research in Education, 42(1), 122-145. https://doi.org/10.3102/0091732X18 759039

Bullock, E. C. (2019). Mathematics curriculum reform as racial remediation: A historical counter-story. In J. Davis \& C. Jett (Eds.), Critical race theory in mathematics education (pp. 75-97). Routledge.

Chmielewski, A. K. (2019). The global increase in the socioeconomic achievement gap, 1964 to 2015. American Sociological Review, 84(3), 517-544. https://doi.org/10.1177/0003122419847165

Coles, J. A. (2020). A BlackCrit re/imagining of urban schooling social education through Black youth enactments of Black storywork. Urban Education, 4, 1-30. https://doi.org/10.1177/0042085920 908919

Davis, J., \& Jett, C. C. (Eds.). (2019). Critical race theory in mathematics education. Routledge.

Dumas, M. J., \& Ross, K. M. (2016). "Be real black for me" imagining BlackCrit in education. Urban Education, 51(4), 415-442. https://doi.org/10.1177/0042085916628611

Enyedy, N., Mukhopadhyay, S., \& Danish, J. (2006, July). At the intersection of statistics and culturally relevant pedagogy: Potential and potential challenges of learning statistics through social activism. In Proceedings of 7th International Conference on Teaching Statistics. Voorburg, The Netherlands: International Statistical Institute. Online: www.stat.auckland.ac.nz/ iase/publications/17/7A1_ENYE.pdf.

Garg, S., Kim, L., Whitaker, M., et al. (2020). Hospitalization rates and characteristics of patients hospitalized with laboratory-confirmed coronavirus disease 2019-COVID-NET, 14 States, March 1-30, 2020. MMWR. Morbidity and mortality weekly report, 69.

Gay, G. (2010). Culturally responsive teaching (2nd ed.). Teachers College Press.

Gholson, M. L., \& Wilkes, C. E. (2017). (Mis) Taken identities: Reclaiming identities of the "collective black" in mathematics education research through an exercise in black specificity. Review of Research in Education, 41(1), 228-252. https://doi.org/10.3102/0091732X16686950

Gutiérrez, R. (2013). The sociopolitical turn in mathematics education. Journal for Research in Mathematics Education, 44(1), 37-68.

Gutiérrez, R. (2018). The need to rehumanize mathematics. In I. Goffney, R. Gutiérrez, \& M. Boston (Eds.), Rehumanizing mathematics for Black, Indigenous, and Latinx students (pp. 1-10). National Council of Teachers of Mathematics.

Gutstein, E., \& Peterson, B. (2013). Rethinking Mathematics: Teaching Social Justice by the Numbers (2nd ed.). Rethinking Schools.

Gutstein, E., Lipman, P., Hernandez, P., \& de los Reyes, R. . (1997). Culturally relevant mathematics teaching in a Mexican American context. Journal for Research in Mathematics Education, 28(6), 709-737.

Hillard, A., III. (1991). Equity, access, and segregation. Teachers College Record, 92(5), 199-213.

Horsford, S. (2011). Learning in a burning house: Educational inequality, ideology, and (dis) integration. Teachers College Press.

Ing, M. (2014). Can parents influence children's mathematics achievement and persistence in STEM careers? Journal of Career Development, 41(2), 87-103.

Jessup, N., Sears, R., \& Matthews, L. (2021). Reengineering hope for an inclusive mathematics education. In P. G. Schrader, D. Carlson, \& D. Anagnostopoulos (Eds.), The Corona chronicles: Necessary narratives in uncertain times (pp. 207-211). DIOPRESS.

Jones, S. (2015). Mathematics teachers' use of the culturally relevant cognitively demanding mathematics task framework and rubric in the classroom. Northeastern Educational Research Association (NERA) Annual Conference Proceedings. Retrieved from http://opencommons.uconn.edu/cgi/viewcontent.cgi? article $=1001 \&$ context $=$ nera 2015

Kantamneni, N. (2020). The impact of the COVID-19 pandemic on marginalized populations in the United States: A research agenda. Journal of Vocational Behavior, 119, 103439. https://doi.org/10.1016/j.jvb. 2020.103439

Kelly, S. (2009). The black-white gap in mathematics course taking. Sociology of Education, 82(1), 47-69.

Ladson-Billings, G. (1994). The dreamkeepers: Successful teachers of African American children. John Wiley \& Sons.

Ladson-Billings, G. (1995a). But that's just good teaching! The case for culturally relevant pedagogy. Theory into Practice, 34(3), 159-165.

Ladson-Billings, G. (1995b). Toward a theory of culturally relevant pedagogy. American Educational Research Journal, 32(3), 465-491.

Ladson-Billings, G. (2006). From the achievement gap to the education debt: Understanding achievement in US schools. Educational Researcher, 35(7), 3-12. 
Ladson-Billings, G., \& Tate, W. (1995). Toward a critical race theory of education. Teachers College Record, 97(1), 47-68.

Larnell, G. V. (2016). More than just skill: Examining mathematics identities, racialized narratives, and remediation among black undergraduates. Journal for Research in Mathematics Education, 47(3), 233-269.

Leonard, J., \& Guha, S. (2002). Creating cultural relevance in teaching and learning mathematics. Teaching Children Mathematics, 9(2), 114-118.

Lund, E. M. (2020). Even more to handle: Additional sources of stress and trauma for clients from marginalized racial and ethnic groups in the United States during the COVID-19 pandemic. Counselling Psychology Quarterly, 1, 10. https://doi.org/10.1080/09515070.2020.1766420

Martin, D. B. (2006). Mathematics learning and participation as racialized forms of experience: African American parents speak on the struggle for mathematics literacy. Mathematical Thinking and Learning, 8(3), 197-229.

Martin, D. B. (2012). Learning Mathematics While Black. Educational Foundation, 26, 47-66.

Martin, D. B. (2013). Race, racial projects, and mathematics education. Journal for Research in Mathematics Education, 44(1), 316-333.

Martin, D. B. (2019). Equity, inclusion, and antiblackness in mathematics education. Race Ethnicity and Education, 22(4), 459-478. https://doi.org/10.1080/13613324.2019.1592833

Martin, D. B., Price, P. G., \& Moore, R. (2019). Refusing systemic violence against Black children: Toward a Black liberatory mathematics education. In J. Davis \& C. Jett (Eds.), Critical Race Theory in Mathematics Education (pp. 32-55). New York: Routledge.

Matthews, L. E. (2003). Babies overboard! The complexities of incorporation culturally relevant teaching into mathematics instruction. Educational Studies in Mathematics, 53(1), 61-82.

Matthews, L. E. (2018). He who feels it, knows it: Rejecting gentrification and trauma for love and power in mathematics for urban communities. Journal of Urban Mathematics Education., 11(1-2), 11-25. https://doi.org/10.21423/jume-v11i1-2a355

Matthews, L. E., Jones, S. M., \& Parker, Y. A. (2013). Advancing a framework for culturally relevant, cognitively demanding mathematics tasks. In J. Leonard \& D. Martin (Eds.), The brilliance of Black children in mathematics: Beyond the numbers and toward new discourse (pp. 123-150). Information Age Publishing.

Matthews, L. E. (2020). Hope Wheel. Retrieved September 20, 2020, from https://loumatthews.live/hopew heel

McGee, E., \& Spencer, M. B. (2015). Black parents as advocates, motivators, and teachers of mathematics. The Journal of Negro Education, 84(3), 473-490.

McNeal, L. R. (2009). The re-segregation of public education now and after the end of Brown v. Board of Education. Education and Urban Society, 41(5), 562-574.

National Governors Association Center for Best Practices, \& Council of Chief State School Officers. (2010). Common Core State Standards for mathematics: Kindergarten introduction. http://www.corestandards. org/Math/Content/K/introduction

Nicola, M., Alsafi, Z., Sohrabi, C., Kerwan, A., Al-Jabir, A., Iosifidis, C., ... \& Agha, R. (2020). The socioeconomic implications of the coronavirus and COVID-19 pandemic: A review. International journal of surgery, 78, 185-193https://doi.org/10.1016/j.ijsu.2020.04.018

Noddings, N. (1984). A feminine approach to ethics and moral education. University of California Press, $177,27$.

Ortiz, N. A., \& Davis, T. J. (2020). Gladyss lesson plan: A culturally relevant exemplar. Mathematics Teacher: Learning and Teaching PK-12, 113(8), 651-657. https://doi.org/10.5951/MTLT.2019.0053

Ortiz, N. A., \& Ruwe, D. (in-press). Black English and mathematics education: A critical look at culturally sustaining pedagogy. Teachers College Record.

Pande, R. (2016). Strategic essentialism. International encyclopedia of geography: People, the Earth, environment and technology: People, the Earth, Environment and Technology, 1-6. https://doi.org/10. 1002/9781118786352.wbieg1170

Paris, D. (2012). Culturally sustaining pedagogy: A needed change in stance, terminology, and practice. Educational Researcher, 41(3), 93-97.https://doi.org/10.3102/0013189X12441244

Peressini, D. D. (1998). The portrayal of parents in the school mathematics reform literature: Locating the context for parental involvement. Journal for Research in Mathematics Education, 29(5), 555-582.

Pi Before Dinner - Math Inspiration Community (n.d.). About [Facebook group]. Facebook. Retrieved September 17, 2020 from https://www.facebook.com/groups/pibeforedinner

Prime, H., Wade, M., \& Browne, D. T. (2020). Risk and resilience in family well-being during the COVID19 pandemic. American Psychologist, 75(5), 631-643. https://doi.org/10.1037/amp0000660

Reich, J. (2019). Teaching our way to digital equity. Educational Leadership, 76(5), 30-35. 
Remillard, J., \& Jackson, K. (2006). Old math, new math: Parents' experiences with standards-based reform. Mathematical Thinking and Learning, 8(3), 231-259.

Resta, P., \& Laferrière, T. (2008). Issues and challenges related to digital equity. In Voogt, K. Jokem, \& Gerald (Eds.), International handbook of information technology in primary and secondary education (pp. 765-778). Springer.

Schnee, E., \& Bose, E. (2010). Parents "don't" do nothing: Reconceptualizing parental null actions as agency. School Community Journal, 20(2), 91-114.

Sleeter, C. E. (1997). Mathematics, multicultural education, and professional development. Journal for Research in Mathematics Education, 28(6), 680-696.

Smith, S. (2020, April, 7). COVID-19 'tremendous' learning gap: Less than 30 percent of students registered for online platforms. Reported for Eyewitness News. Retrieved from https://ewnews.com/covid19-tremendous-learning-gap-less-than-30-percent-of-students-registered-for-online-platform

Stash, S., \& Hannum, E. (2001). Who goes to school? Educational stratification by gender, caste, and ethnicity in Nepal. Comparative Education Review, 45(3), 354-378.

Tate, W. F. (1995). Returning to the root: A culturally relevant approach to mathematics pedagogy. Theory into Practice, 34(3), 166-173.

Tate, W. (2004). Chapter 5: Brown, political economy, and the scientific education of African Americans. Review of Research in Education, 28(1), 147-184.

Turner, E. E., \& Strawhun, B. T. (2007). Students use math to confront overcrowding. Rethinking Our Classrooms: Teaching for Equity and Social Justice, 1, 63-67.

United States Census Bureau (2020). Children characteristics report. https://data.census.gov/cedsci/ table?q=children\%20by\%20race\&tid=ACSST1Y2019.S0901

Unterhalter, E. (2005). Global inequality, capabilities, social justice: The millennium development goal for gender equality in education. International Journal of Educational Development, 25(2), 111-122.

U.S. Congress. Joint Economic Committee. (2017, September 27). The 2017 Joint Economic Report: America's digital divide. Retrieved from https://www.jec.senate.gov/public/_cache/files/ff7b3d0b-bc004498-9f9d-3e56ef95088f/the-digital-divide-.pdf

van Dorn, A., Cooney, R. E., \& Sabin, M. L. (2020). COVID-19 exacerbating inequalities in the US. Lancet (London, England), 395(10232), 1243. https://doi.org/10.1016/S0140-6736(20)30893-X

Wagner, D., Bakker, A., Meaney, T., Mesa, V., Prediger, S., \& Van Dooren, W. (2020). What can we do against racism in mathematics education research? Educational Studies in Mathematics, 104(3), 299311. https://doi.org/10.1007/s10649-020-09969-w

Warren, C. A., \& Coles, J. A. (2020). Trading spaces: Antiblackness and reflections on Black education futures. Equity \& Excellence in Education, 53, 1-17. https://doi.org/10.1080/10665684.2020.1764882

Yang, J., \& Carter, S. (2020). Loss, grief, and racial health disparities during COVID-19: Same storm, different boats. Journal of Interdisciplinary Perspectives and Scholarship, 3(1), 5.

Yosso, T. J. (2005). Whose culture has capital? A critical race theory discussion of community cultural wealth. Race Ethnicity and Education, 8(1), 69-91.

Publisher's note Springer Nature remains neutral with regard to jurisdictional claims in published maps and institutional affiliations. 